\title{
Endocrine management of children with Prader-Willi syndrome
}

This article was published in the following Dove Press journal:

Pediatric Health, Medicine and Therapeutics

21 October 2013

Number of times this article has been viewed

\section{Clarice Borschiver \\ Medeiros' \\ Ana Paula Bordallo' \\ Flavio Moutinho Souza ${ }^{2}$ \\ Paulo Ferrez Collett- \\ Solberg ${ }^{1,3}$ \\ 'Endocrinology Unit, Departamento de Medicina Interna, Faculdade de Ciências Médicas, Universidade do Estado do Rio de Janeiro (UERJ), Rio de Janeiro, Brazil; ${ }^{2}$ Pediatric Endocrinology Unit, Departamento de Pediatria, Hospital Federal Cardoso Fontes - Ministério da Saúde do Brasil, Brasília, Brazil; ${ }^{3}$ Laboratório de Pesquisas Clínicas e Experimentais em Biologia Vascular (BioVasc), Universidade do Estado do Rio de Janeiro (UERJ), Rio de Janeiro, Brazil}

Correspondence: Paulo Ferrez Collett-Solberg

Laboratório de Pesquisas Clínicas e Experimentais em Biologia Vascular (BIOVASC), Centro Biomédico, UERJ, Pavilhão Reitor Haroldo Lisboa da Cunha (térreo), Rua São Francisco Xavier, 524, 20550-0 I3, Rio de Janeiro, RJ, Brazil Tel +55 2123340696

Fax +552123340692

Email paulosolberg@yahoo.com
Abstract: Prader-Willi syndrome is a rare genetic condition afflicting nearly 1/15,000 live births. Clinical features include neonatal hypotonia, poor weight gain in early infancy followed by binge eating from childhood to adulthood, severe obesity, developmental delay, short stature, and hypogonadism of both central and peripheral etiology. Central hypothyroidism and adrenal insufficiency may occur. Sleep disordered breathing, by obstruction of upper airways associated with central hypoventilation, is a common feature. Most of these characteristics are assumed to be the result of a hypothalamic dysfunction. The most important complication and the most difficult to manage is the obesity. This review aims at discussing the most recent strategies to manage the endocrine complications of Prader-Willi syndrome patients, with a special approach on the treatment of obesity, hypogonadism, and short stature. We summarize the indication and effects of recombinant human growth hormone therapy on growth, cognitive development, and body composition, and discuss the effects of recombinant human growth hormone therapy on the resulting sleep disorders.

Keywords: Prader-Willi syndrome, obesity, hypogonadism, growth hormone, sleep disorder

\section{Introduction}

Prader-Willi syndrome (PWS) is a rare genetic disorder caused by a lack of expression of paternally inherited imprinted genes located on chromosome 15q11-q13, and it is characterized by hypothalamic dysfunction. ${ }^{1}$ The clinical findings include dysmorphic facial features (thin upper lip and almond-shaped eyes), neonatal hypotonia, poor sucking and weight gain in early infancy followed by binge eating and severe obesity, developmental delay, short stature, small hands and feet, and hypogonadism. Other endocrine deficiencies may occur, such as hypothyroidism and partial adrenal insufficiency. Most of these features are assumed to be the result of hypothalamic dysfunction. Due to the association of hypotonia and obesity, sleep apnea is a major concern. $^{2}$

PWS has a similar prevalence between genders and occurs worldwide with an incidence of $1 / 15,000$ to $1 / 25,000 .{ }^{3}$ It should be suspected in all children with severe hypotonia at birth, as well as among children who have difficulty gaining weight in the first year of life, and signs of hypogonadism like cryptorchidism and micropenis..$^{4,5}$ These children should be referred for molecular testing for definitive diagnosis.

The most common genetic finding ( $70 \%$ of cases) in this population is the deletion of paternally inherited genes, followed by ( $25 \%$ of cases) maternal uniparental disomy (when the child receives both copies of chromosome 15 from the mother and none from the father). Five percent of cases are due to errors of imprinting, and in rare cases is 
associated with a translocation, which moves the gene away from the center of the imprinting region. ${ }^{6}$ The most common method to diagnose PWS is fluorescence in situ hybridization, although the most accurate method is deoxyribonucleic methylation analysis.

In the long term, the greatest challenge faced by the caregivers and the health professionals involved with these patients is how to control the severe obesity and its metabolic complications. The awareness about this problem should start as early as the PWS diagnosis is made, even during the period when the affected individual experiences difficulty gaining weight, and this symptom is of capital importance since it represents the major cause of morbidity and mortality of these patients. ${ }^{7,8}$

The objective of this review is to discuss the most recent strategies to manage the endocrine complications found in PWS.

\section{Obesity}

The natural history of PWS is marked by distinct nutritional stages. Classically divided into two stages (poor feeding and overfeeding), the nutritional phases of children with PWS are more complex. In 2011 Miller et $\mathrm{al}^{9}$ identified up to seven phases. The first of these phases is intrauterine, where fetuses with PWS have decreased fetal movements and growth restriction compared to unaffected siblings (PWS children are $15 \%-20 \%$ smaller than their unaffected siblings). During the next two phases, which are detected in the first years of life, the child is not obese. These phases that are characterized by normal weight are followed by the four phases where the PWS patient is already obese, although he or she is exhibiting different behaviors towards caloric intake. ${ }^{9}$ During the first year of life, hypotonia with severe difficulty to feed with or without failure to thrive is characteristic. During infancy, most patients with PWS weigh between the 25th and the 75 th percentile of the growth chart for healthy children. Later, there is a gradual increase in weight gain, initially without noticeably significant changes in appetite or caloric gain. After 5 years of age, the PWS patient goes into a phase of hyperphagia, which is typically accompanied by a lack of fullness and binge eating. During this period, the child presents with behavioral changes related to diet, which include actively seeking food, eating inedible food (animal feed, spoiled food, decor that mimics food, garbage, and so on), stealing food or money to purchase food, and even escaping from home to actively pursue aliments. ${ }^{10-12}$ The cause for the delay in the development of the hyperphagia and changes in feeding behavior remains uncertain, and it is most possibly related to delayed or abnormal central nervous system development, rather than hormonal peripheral signaling alterations. ${ }^{13}$ Ghrelin, although increased in patients with PWS, does not seem to play an important role in the etiology of obesity in these patients. ${ }^{14}$

The amount of calories ingested is not the only characteristic that leads to obesity in PWS patients. When compared with other individuals with similar weight and body mass index (BMI), PWS patients have lower resting energy expenditure. They also have differences in the leanto-fat mass ratio and in fat distribuition. ${ }^{15}$ Even though the lean-to-fat mass ratio favors the fat mass, with reduced lean body mass and increased fat mass, PWS patients seem to be partially protected from the metabolic complications associated with the degree of obesity. A study by Goldstone et al evaluated the distribution of adipose tissue in obese women with and without PWS through magnetic resonance imaging and revealed a peculiar pattern of visceral fat distribution in carriers of the syndrome, with decreased visceral adipose tissue and increased subcutaneous adipose tissue. ${ }^{16}$ It has been proposed that these patients have lower serum insulin and insulin resistance when compared to their peers. Thus, the relative decrease of visceral fat appears to protect patients with PWS from some obesity-related complications. ${ }^{16,17}$ However, type 2 diabetes (25\%), hypertension and cardiovascular disease $(38 \%)$ are described in adults with PWS. ${ }^{18}$

Grugni et al ${ }^{19}$ compared the frequency of metabolic syndrome components in 108 adult patients with PWS (87 obese patients and 21 nonobese patients) with 85 obese nonsyndromic patients. The study revealed that obese patients with PWS have a higher frequency of hyperglycemia and elevated systolic blood pressure when compared with obese controls. However, the presence of metabolic syndrome was higher in controls $(45.9 \%)$ than in both nonobese patients with PWS (4.8\%) and obese PWS patients $(41.4 \%) .{ }^{19}$

The management of obesity in PWS involves early diagnosis, the use of a low calorie balanced diet, monitoring with a multidisciplinary team, family psychological counseling, and behavioral guidance regarding the disease and the inevitable hyperphagia. The tools used to control weight gain include strict supervision with controlled access to food and regular exercise. Recombinant human growth hormone (rhGH) therapy may help since it may reduce fat mass, increase muscle mass, increase muscular tone, and consequently increase energy expenditure, although it does not change hyperphagia. ${ }^{12}$

Maintaining adequate nutrition and appropriate monitoring of weight gain in children with PWS at any age is 
essential. This goal is achieved through behavioral and dietary management; thus, the diet should be adjusted to maintain an adequate weight for the patient's age. When the hyperphagic behavior begins, calories should be restricted to $60 \%$ of the calories recommended for each patient's age group. ${ }^{3}$ The recommended diet consists of $30 \%$ fat, $45 \%$ carbohydrates, and $25 \%$ protein, with at least 20 grams of fiber per day. ${ }^{3}$ In the study by Miller et al, ${ }^{20} 33 \mathrm{PWS}$ patients who had undergone this diet had more success in terms of weight management than those having only a restricted amount of total calories.

Regarding behavioral change, it is extremely important to restrict access to food and, if necessary, the locking of cabinets and refrigerators is indicated. Moreover, caregivers should avoid exposure of children to places that suggest eating, encourage a routine in terms of when and what to eat, and caregivers should also be instructed to avoid offering food to the child. ${ }^{3}$

The practice of sports and physical activity is essential for the patient with PWS, since it stimulates energy expenditure, promotes socialization, and increases muscle tone. The choice of sports should be individualized according to the local availability and preference of the child; moreover, the routine of the patient with PWS should include at least 30 minutes of participation in some form of physical activity, including sports, 4-5 days per week.

Published controlled trials showed no evidence of benefits in terms of the pharmacological treatment of hyperphagia with anorectic agents such as sibutramine or topiramate. ${ }^{12}$ Studies describing the use of agents that could reduce serum ghrelin levels, like somatostatin, also failed to demonstrate any benefit in PWS. ${ }^{21,22}$ A recent study with glucagon-like peptide-1 analog in eight patients with PWS showed a sharp increase in satiety and insulinotropic effects, as well as a decrement in serum glucose ${ }^{23}$ However, further studies are necessary to assess the safety and efficacy of this class of drugs, since it causes delayed gastric emptying and results in an increased risk of gastric necrosis and/or rupture secondary to binge eating. . $^{2425}$

Bariatric surgery and gastric banding or bypass, as alternatives for the treatment of severe obesity in patients with PWS, have disappointing results, since these procedures do not reduce hyperphagia and do not cause weight loss over a long period of time. ${ }^{13,26-29}$ It is noteworthy that these procedures are still associated with high mortality, since the patient with PWS has greater resistance to pain, reduced satiety, autonomic dysfunction, delayed gastric emptying, decreased ability to vomit, self-flagellation, sleep disorders, and increased risk during anesthetic induction. ${ }^{26-29}$ Thus, there is little justification for using bariatric surgery as routine treatment in severely obese patients with PWS.

\section{Hypogonadism}

The majority of patients with PWS have clinical signs of hypogonadism from birth, such as cryptorchidism, which is present in $80 \%-90 \%$ of cases; ${ }^{30}$ micropenis; and hypoplasia of the scrotum, of the clitoris, and of the labia minora. In adolescence, delayed pubertal development or incomplete puberty is common, although there are reports in the literature of premature adrenarche and precocious puberty. ${ }^{31,32}$

The common knowledge is that PWS patients have hypogonadotropin hypogonadism due to hypothalamic dysfunction, with normal prepubertal testicular histology documented. ${ }^{11,30,6}$ Currently, however, there is evidence that primary testicular dysfunction, mainly due to tubular injury, greatly contributes to the hypogonadism observed in boys. ${ }^{33,34}$ In a study published in 2012, Siemensma et $\mathrm{al}^{33}$ followed 68 patients with PWS for 8 years (with a mean age of 3.4 years at the initial visit), and noted that after the onset of puberty, inhibin B levels declined to below the 5th percentile, and follicle-stimulating hormone (FSH) levels increased to above the 95th percentile. Testosterone levels increased, but remained below the 5 th percentile, suggesting primary testicular failure. ${ }^{33}$ In women, there is greater phenotypic variability in relation to ovarian function. ${ }^{35}$ Recently Radicioni et $\mathrm{al}^{36}$ and Gross-Tsur et $\mathrm{al}^{37}$ confirmed the heterogeneity of the reproductive hormone profile in patients with PWS.

After the clinical or genetic diagnosis, proper management of cryptorchidism is extremely important since there is evidence of early damage of germ cells. ${ }^{38}$ The Committee on Genetics of the American Academy of Pediatrics recommends the use of chorionic gonadotropin prior to definitive surgical treatment to avoid possible deleterious effects of general anesthesia in children with muscular hypotonia. ${ }^{3}$ In addition, chorionic gonadotropin can increase the size of the scrotum and partially normalize the length of phallus, improving surgical outcomes. Preferably, this should be initiated between 6 months and 12 months of age. During clinical treatment, it is important to follow serum testosterone levels and testicular ultrasound. If medical treatment is not successful, it is recommended that orchiopexy be conducted before the patient reaches 2 years of age.

During puberty, hormone replacement therapy should be considered for the induction, promotion, and maintenance of puberty with the goal of preventing decreased bone mineral density (BMD). There is no consensus as to the most appropriate regimen for sex hormone replacement; however, before 
any treatment is used, it is important to document serum levels of luteinizing hormone (LH), FSH, estradiol (in girls) or testosterone (in boys), as well as conducting pelvic (girls) or testicular (boys) ultrasound and bone densitometry. ${ }^{39}$ Based on initial results, serum levels of luteinizing hormone, FSH, and gonadal steroids (estradiol or testosterone) should be obtained after gonadotropin-releasing hormone stimulation. For induction of puberty in boys, monthly intramuscular injection of testosterone is used, with a gradual increase to adult doses at the end of puberty. Unfortunately, side effects cannot be ignored, especially in males. In healthy men, testosterone in high doses might induce aggressive behavior and psychotic disorders, ${ }^{40,41}$ and the PWS population seems to be at greater risk. The initial dose in PWS patients should be one-third to one-half of the normally recommended androgen dose, with the objective of trying to prevent the aggressive behavior occasionally seen in some individuals. ${ }^{42}$ Larger prospectively controlled studies are still necessary in order to determine the impact of androgen replacement in this population. It is important to point out that psychologically, adolescence is a critical period in PWS, with psychotic episodes occurring in one-fifth of young adults; ${ }^{40,41,43}$ however, the worsening of temper tantrums or aggressive behavior were not confirmed in a study by Eiholzer et al. ${ }^{44}$

In girls, conjugated estrogens or oral/transdermal estradiol are also used through a gradual increase. After 1-2 years of treatment, or if uterine bleeding occurs, progesterone is administered in association with estrogens in the last 10 days of the cycle. Attention should be drawn to the fact that estrogen replacement therapy is related to thrombotic events, and the risk of ischemic cerebrovascular disease in PWS is increased even in nonobese subjects. ${ }^{45,27}$ During adolescence, patients with greater cognitive impairment should always be supervised because of the risk of sexual abuse. The patients' cognitive dysfunction, social and emotional immaturity, and the risk of Angelman syndrome in the offspring of PWS mothers contribute to advising against pregnancy among PSW patients. ${ }^{42}$ Mental retardation alone should not be a contraindication for allowing normal pubertal development to occur, or to preclude sex hormone replacement at any age in affected individuals. ${ }^{42}$ As adults, women with PSW have amenorrhea or oligomenorrhea, and infertility is the rule in both genders; however, there are reports of pregnancy in women with genetically documented PWS, ${ }^{46}$ while at the time of the preparation of this manuscript there were no reports about paternity.

\section{Osteoporosis and bone density}

Patients with PWS seem to have low BMD - probably due to growth hormone $(\mathrm{GH})$ and sex steroid deficiencies - as well as low muscular activity. Adults with PWS present a high prevalence of osteoporosis. ${ }^{47,48}$ A study by Vestergaard et al ${ }^{49}$ evaluated the BMD and biochemical markers of bone turnover of eight patients with PWS (mean age of 24 years), and compared these markers with those of age-, sex- and BMI-matched controls. The results revealed that patients with PWS had lower whole-body BMD due to lower bone mineral content (BMC). The researchers also found that resorptive and formative bone markers were significantly elevated in PWS patients. ${ }^{49}$ In children, the bone mineral content is also reduced when compared with children with similar BMI. Rubin et al ${ }^{50}$ compared the body composition of twelve children (8-11 years) with PWS who were not GH-naïve with that of obese and lean controls. The authors studied BMC, BMD, and the BMD $z$ score for the patient's total body, hips, and lumbar spine. The authors found significantly lower BMC and BMD in those with PWS compared to obese controls, but there were no differences between PWS and lean controls. ${ }^{50}$

At the moment, there are no protocols for the prevention of osteoporosis in adolescents or adults with PWS, although with the use of rhGH from an early age and the improvement in muscular tone and physical activity, the body composition of these patients may improve not only by reducing the weight gain, but also by increasing their bone mass.

\section{Hypothyroidism}

Patients with PWS may develop hypothyroidism, both central and primary, congenital or acquired. ${ }^{51}$ Due to the clinical characteristics of PWS, the clinical diagnosis of hypothyroidism may be difficult. Therefore, it is important to periodically review the thyroid function by obtaining serum levels of thyroid-stimulating hormone, free T4, and total T4. Levothyroxine replacement therapy should be initiated as soon as hypothyroidism is diagnosed. ${ }^{52}$

\section{Adrenal insufficiency}

Several studies point to an estimated mortality rate in PWS of 3\% per year. ${ }^{53-55}$ Changes in the hypothalamic-pituitaryadrenal axis may be responsible, since under stress or aggravating factors, the adrenal response is inadequate or delayed in some patients. In 2008, de Lind van Wijngaarden et $\mathrm{al}^{56}$ investigated the hypothalamic-pituitary-adrenal axis in children with PWS using a single metyrapone dose as a stimulus, and the authors reported a high prevalence of central adrenal insufficiency in these patients. Other investigators using low- or high-dose adrenocorticotropic hormone stimulation tests or insulin tolerance tests found 
a normal adrenal axis or a smaller prevalence of central adrenal insufficiency. ${ }^{57-59}$

At the moment, there are no data supporting the routine treatment of all PWS patients with glucocorticoid replacement doses. Treatment with hydrocortisone during stress should be provided to those who had no evidence of normal adrenal function. Maintenance therapy is performed only in patients with clinical symptoms of adrenal insufficiency.

\section{Short stature}

Short stature is one of the capital characteristics of PWS. If they are left untreated, patients will reach an average adult height of $155 \mathrm{~cm}$ for males and $148 \mathrm{~cm}$ for females. ${ }^{60,61}$ Wollmann et $\mathrm{al}^{62}$ analyzed the growth pattern of 315 patients and found nearly normal growth in the first year, followed by decreased growth velocity, resulting that from 3 to 13 years old the 50th percentile of PWS growth chart is overlapped with the 3rd percentile of the growth chart of normal population. Furthermore, children with PWS have a subnormal pubertal growth spurt. ${ }^{62}$ It has been hypothesized that children with PWS have some degree of hypothalamic GH deficiency, ${ }^{63}$ which was demonstrated by studies that showed a blunted GH secretory pattern after pharmacological stimulus and low serum insulin-like growth factor-1 levels. ${ }^{64}$

In addition, rhGH treatment has been approved by the United States Food and Drug Administration for PWS patients since $2000 .{ }^{65} \mathrm{~A}$ study conducted with 22 patients with PWS within the Kabi International Growth Study (KIGS) cohort found that the first year of rhGH treatment improved height from a median pretreatment of -1.6 standard deviation score (SDS) to -0.4 SDS, and that by the age of 18.1 years, patients had attained an adult height of -0.5 SDS for girls and -0.9 SDS for boys. ${ }^{66}$

When compared to both normal-weight control subjects and BMI-matched nonsyndromic obese subjects, patients with PWS had reduced lean body mass, increased fat mass, and decreased BMC, ${ }^{67}$ all of which may also be exacerbated by GH insufficiency and hypogonadism. Besides restoring normal adult height, treatment with rhGH improves body composition by increasing muscle mass and decreasing body fat percentage, improving respiratory muscle function, physical strength, and agility. ${ }^{68}$ However, few long-term prospective studies have analyzed the rhGH effects over more than 2 years. Carrel et $a^{168}$ investigated the effect of 4 years of rhGH. They first evaluated the 24-month response to rhGH therapy with a single regimen consisting of rhGH in doses of $1.0 \mathrm{mg} / \mathrm{m}^{2}$ Per day. ${ }^{68}$ During the next 24 months, patients were randomized to three different dosage regimens: $0.3 \mathrm{mg} / \mathrm{m}^{2}$ per day, $1.0 \mathrm{mg} / \mathrm{m}^{2}$ per day, and $1.5 \mathrm{mg} / \mathrm{m}^{2}$ per day ${ }^{69}$ Their data showed that after 4 years of rhGH therapy, the early improvements in decreasing body fat and increasing lean body mass were attenuated by the low-dose regimen of $0.3 \mathrm{mg} / \mathrm{m}^{2}$ per day, and these results were increased by the high-dose regimen of $1.5 \mathrm{mg} / \mathrm{m}^{2}$ per day and were sustained by the medium-dose regimen of $1.0 \mathrm{mg} / \mathrm{m}^{2}$ per day, suggesting a positive dose-response effect. ${ }^{69}$ No major side effects were reported in the 4-year follow-up of this study. ${ }^{69}$ The metabolic effects of rhGH continue even after the discontinuation of the treatment. Coupaye et $\mathrm{al}^{70}$ compared patients who had received rhGH during childhood and adolescence (discontinued 7.0 \pm 4.4 years prior to the study) with patients not treated with rhGH. They analyzed the body composition, insulin and glucose levels in nondiabetic patients, as well as and the diabetes control in patients with diabetes. The authors concluded that rhGH treatment in childhood and adolescence was associated with significantly decreased BMI, as well as with improved body composition and metabolic status in adults with PWS. ${ }^{70}$

In addition, rhGH treatment induces cognitive changes as well. Some studies have demonstrated improvements in cognitive function, ${ }^{71-73}$ and one study demonstrated that in randomized controlled studies, rhGH prevents cognitive deterioration in patients who were not treated. ${ }^{71}$ In terms of motor performance, although physical training is of great importance, one review indicated that most studies showed that the use of rhGH facilitates the improvement of physical training in this population, decreasing any differences between PWS and the normal population. ${ }^{72}$

Prior to the initialization of rhGH therapy, children with PWS must undergo a thorough clinical evaluation including anthropometric status (weight, height, BMI, waist circumference, and skinfold thickness); laboratorial assessment of metabolic status (glucose and lipid metabolism; hepatic enzymes, abdominal ultrasound; liver biopsy, if necessary); polysomnographic evaluation of sleep disorders; and spine $\mathrm{X}$-ray for scoliosis appraisal. ${ }^{12,73}$ Bell et al ${ }^{74}$ reviewing the safety profile of rhGH in children (not specific to PWS children), reported possible adrenal insufficiency crisis events in patients after the start of rhGH treatment since all reported patients, except one who had idiopathic panhypopituitarism, had organic causes for GH deficiency. It should be noted that none of those patients had PWS. ${ }^{74}$ More data is required on the risk assessment of adrenal crisis induction after the initiation of treatment with rhGH in patients with PWS. 
On a similar topic, an initial report suggested that $\mathrm{rhGH}$ could be worsening sleep apnea and could be leading to premature death of children with PWS receiving rhGH. ${ }^{75}$

\section{Sleep disorders}

Pathophysiology of sleep disordered breathing (SDB) in PWS seems to be multifactorial, including both peripheral and central mechanisms. Hypotonia, facial dysmorphisms, and tonsillar hypertrophy may cause a reduction in the diameter of the upper airways; while fat deposition, respiratory muscle hypotonia, and kyphoscoliosis are related to ventilatory restrictive syndrome; and low response to partial pressure of $\mathrm{CO}_{2}$ leads to central hypoventilation and hypercarbia. ${ }^{76}$ Even nonobese patients are at an increased risk of developing SDB, and some issues such as central apnea may be present as early as during the first year of life. ${ }^{77,78}$ Sudden death, especially during sleep, has been widely reported as one of the major causes of death in PWS..$^{8,53,79-81}$ Most of the deaths were related to respiratory problems like respiratory tract infection, adenoid and tonsil hypertrophy, and sleep apnea.

Seventy percent of PWS patients present some degree of SBD. ${ }^{82}$ Obstructive sleep apnea (OSA) is a primary disorder, and is considered a minor criterion for the diagnosis of PWS. ${ }^{83}$ OSA may lead to cardiovascular complications, such as systemic arterial hypertension and cor pulmonale, with increased severity and a high impact on morbimortality. ${ }^{12}$ In PWS patients, OSA may also be related to autistic behavior and impulsivity. ${ }^{82}$ Excessive daytime sleepiness and rapid eye movement sleep abnormalities are common issues in PWS and can be considered primary disorders, although OSA may aggravate them. ${ }^{12}$ DeMarcantonio et a ${ }^{84}$ retrospectively evaluated the need for tonsillectomy in PWS patients with OSA. Despite symptomatic improvements associated with a lower apnea/hypopnea index (16.4 versus 4.4, respectively before and after surgery), the difference did not reach statistical significance, possibly because of the small number of cases analyzed. ${ }^{84}$

\section{rhGH and sleep disorders}

It has been suggested that rhGH therapy might aggravate tonsillar hypertrophy, resulting in a worsening of OSA, which would be responsible for the emergence of sudden death. ${ }^{76-80} \mathrm{~A}$ series of studies have been published with the purpose of establishing the relationship between rhGH treatment and breathing disorders. ${ }^{76-80}$ However, two prospective studies pointed to improvements in response to the partial pressure of $\mathrm{CO}_{2}$, in ventilation patterns at rest, in upper airway obstruction, and in accessory respiratory muscle tonus throughout the treatment. ${ }^{85,86}$
Regarding the apnea-hypopnea index, two other studies described improvement on sleep abnormalities in overnight polysomnography after 6 months of rhGH therapy, but without reaching statistical significance. ${ }^{87,88}$ Nonetheless, some patients had obstructive symptoms and the OSA worsened, which was mostly attributed to upper airway infections, tonsillar hypertrophy, and high levels of insulin-like growth factor-1. ${ }^{77}$ The initial worsening was not confirmed in some patients after a follow-up polysomnography. Although safety issues have been raised after case reports of worsening OSA during rhGH treatment have been reported, ${ }^{76,80,89}$ and following improvement of obstructive symptoms after withdrawal of the therapy ${ }^{89}$ prospective studies with larger cohorts have failed to show an increased mortality risk. ${ }^{77,90}$ In fact, one nocturnal sudden death was observed in studies by both Festen et $\mathrm{al}^{17}$ (out of 53 patients) and de Lind van Wijngaarden et $\mathrm{al}^{90}$ (out of 55 patients), and both of the patients had previous, near normal polysomnography.

The effect of rhGH in young children with PWS was investigated in a prospective clinical case series study. ${ }^{91}$ Sixteen patients with a median age of 16 months at enrollment were followed. The authors concluded that rhGH improved arterial oxygenation and cardiovascular function during sleep. ${ }^{91}$

In the February 2013 issue of The Journal of Pediatrics, Al-Saleh et a ${ }^{92}$ presented the follow-up data of 15 children with PWS before and up to 2 years after starting rhGH. While two patients had to discontinue rhGH due to respiratory problems, the authors concluded that if there are no signs of SDB before and 6 weeks after the initiation of rhGH, the risk of developing SDB after that is small. ${ }^{92}$ In one of the editorials, Whitman and Myers reviewed the published data and stated that:

Although sleep disordered breathing is essentially ubiquitous in the population with PWS, there is little evidence that initiating rhGH increases that risk in most patients.

Nonetheless, in some patients there does appear to be an increased risk of obstructive events. ${ }^{93}$

Thus, given the high prevalence of SDB in patients with PWS, it is recommended that polysomnography be performed, especially for the investigation of OSA, regardless of symptoms and indication of rhGH treatment. The evaluation of ear, nose, and throat should be requested whenever needed. ${ }^{12}$ In addition, if rhGH therapy is instituted, polysomnography should be performed before and during treatment, so as to detect a possible worsening of the obstructive pattern. Since most of the deaths in patients receiving rhGH occurred in the first months 
of therapy, the initial rhGH dose should be one-fourth to onethird of the maintenance dose, and over a period of months, the dose should be slowly increased to full maintenance. In severe cases of obesity or obstructive symptoms, the focus should be aimed at improving complications before recommending hormone therapy.

\section{Conclusion}

PWS patients have increased mortality due to their hypothalamic dysfunction causing hypoventilation, hypotonia, and obesity. The main goal in the follow-up of these children is to improve motor function and prevent obesity. Supporting and orienting their caregivers is of utmost importance. Controlling patients' weight gain (which is insufficient in the first year of life, and becomes excessive after infancy) requires tremendous effort. The use of rhGH helps in several aspects, although it has to be done under strict surveillance.

As we improve their motor skills in infancy and decrease the patients' weight gain, we can provide them with improved quality of life throughout their prolonged lifespan.

\section{Disclosure}

The authors report no conflicts of interest in this work.

\section{References}

1. Prader A, Labhart A, Willi H. Ein syndrom von adipositas, kleinwuchs, kryptorchismus und oligophrenie nach myotonieartigem zustand im neugeborenenalter. Schweiz Med Wochenschr. 1956;86: 1260-1261.

2. Cassidy SB, Dykens E, Williams CA. Prader-Willi and Angelman syndromes: sister imprinted disorders. Am J Med Genet. 2000;97(2): 136-146.

3. McCandless SE; Committee on Genetics. Clinical report - health supervision for children with Prader-Willi syndrome. Pediatrics. 2011;127(1):195-204.

4. Gunay-Aygun M, Schwartz S, Heeger S, O’Riordan MA, Cassidy SB. The changing purpose of Prader-Willi syndrome clinical diagnostic criteria and proposed revised criteria. Pediatrics. 2001;108(5):E92.

5. Whittington J, Holland A, Webb T, Butler J, Clarke D, Boer H. Relationship between clinical and genetic diagnosis of Prader-Willi syndrome. J Med Genet. 2002;39(12):926-932.

6. Glenn CC, Driscoll DJ, Yang TP, Nicholls RD. Genomic imprinting: potential function and mechanisms revealed by the Prader-Willi and Angelman syndromes. Mol Hum Reprod. 1997;3(4):321-332.

7. Butler JV, Whittington JE, Holland AJ, Boer H, Clarke D, Webb T. Prevalence of, and risk factors for, physical ill-health in people with Prader-Willi syndrome: a population-based study. Dev Med Child Neurol. 2002;44(4):248-255.

8. Whittington JE, Holland AJ, Webb T, Butler J, Clarke D, Boer H. Population prevalence and estimated birth incidence and mortality rate for people with Prader-Willi syndrome in one UK Health Region. J Med Genet. 2001;38(11):792-798.

9. Miller JL, Lynn CH, Driscoll DC, et al. Nutritional phases in PraderWilli syndrome. Am J Med Genet A. 2011;155A(5):1040-1049.

10. Miller JL. Approach to the child with Prader-Willi syndrome. J Clin Endocrinol Metab. 2012;97(11):3837-3844.
11. Butler JV, Whittington JE, Holland AJ, McAllister CJ, Goldstone AP. The transition between the phenotypes of Prader-Willi syndrome during infancy and early childhood. Dev Med Child Neurol. 2010;52(6): e88-e93.

12. Goldstone AP, Holland AJ, Hauffa BP, Hokken-Koelega AC, Tauber M; speakers contributors at the Second Expert Meeting of the Comprehensive Care of Patients with PWS. Recommendations for the diagnosis and management of Prader-Willi syndrome. J Clin Endocrinol Metab. 2008;93(11):4183-4197.

13. Bereket A, Kiess W, Lustig RH, et al. Hypothalamic obesity in children. Obes Rev. 2012;13(9):780-798.

14. Goldstone AP. The hypothalamus, hormones, and hunger: alterations in human obesity and illness. Prog Brain Res. 2006;153:57-73.

15. Miller JL, Lynn CH, Shuster J, Driscoll DJ. A reduced-energy intake, well-balanced diet improves weight control in children with PraderWilli syndrome. J Hum Nutr Diet. 2013;26(1):2-9.

16. Goldstone AP, Brynes AE, Thomas EL, et al. Resting metabolic rate, plasma leptin concentrations, leptin receptor expression, and adipose tissue measured by whole-body magnetic resonance imaging in women with Prader-Willi syndrome. Am J Clin Nutr. 2002;75(3):468-475.

17. Goldstone AP, Thomas EL, Brynes AE, et al. Visceral adipose tissue and metabolic complications of obesity are reduced in Prader-Willi syndrome female adults: evidence for novel influences on body fat distribution. J Clin Endocrinol Metab. 2001;86(9):4330-4338.

18. Goldstone AP. Prader-Willi syndrome: advances in genetics, pathophysiology and treatment. Trends Endocrinol Metab. 2004;15(1):12-20.

19. Grugni G, Crinò A, Bedogni G, et al. Metabolic syndrome in adult patients with Prader-Willi syndrome. Nutr Metab Cardiovasc Dis. 2012.

20. Miller JL, Lynn CH, Shuster J, Driscoll DJ. A reduced-energy intake, well-balanced diet improves weight control in children with PraderWilli syndrome. J Hum Nutr Diet. 2013;26(1):2-9.

21. Tan TM, Vanderpump M, Khoo B, Patterson M, Ghatei MA, Goldstone AP. Somatostatin infusion lowers plasma ghrelin without reducing appetite in adults with Prader-Willi syndrome. J Clin Endocrinol Metab. 2004;89(8):4162-4165.

22. De Waele K, Ishkanian SL, Bogarin R, et al. Long-acting octreotide treatment causes a sustained decrease in ghrelin concentrations but does not affect weight, behaviour and appetite in subjects with Prader-Willi syndrome. Eur J Endocrinol. 2008;159(4):381-388.

23. Sze L, Purtell L, Jenkins A, et al. Effects of a single dose of exenatide on appetite, gut hormones, and glucose homeostasis in adults with Prader-Willi syndrome. J Clin Endocrinol Metab. 2011;96(8): E1314-E1319

24. Stevenson DA, Heinemann J, Angulo M, et al. Gastric rupture and necrosis in Prader-Willi syndrome. J Pediatr Gastroenterol Nutr. 2007;45(2):272-274.

25. Wharton RH, Wang T, Graeme-Cook F, Briggs S, Cole RE. Acute idiopathic gastric dilation with gastric necrosis in individuals with Prader-Willi syndrome. Am J Med Genet. 1997;73(4):437-441.

26. De Peppo F, Di Giorgio G, Germani M, et al. BioEnterics intragastric balloon for treatment of morbid obesity in Prader-Willi syndrome: specific risks and benefits. Obes Surg. 2008;18(11):1443-1449.

27. Scheimann AO, Butler MG, Gourash L, Cuffari C, Klish W. Critical analysis of bariatric procedures in Prader-Willi syndrome. J Pediatr Gastroenterol Nutr. 2008;46(1):80-83.

28. Scheimann A, Butler MG, Stevenson D, Miller JL, Cuffari C, Klish WJ. "Efficacy of laparoscopic sleeve gastrectomy as a stand-alone technique for children with morbid obesity" and "BioEnterics intragastric balloon for treatment of morbid obesity in Prader-Willi syndrome: specific risks and benefits". Obes Surg. 2009;19(5):671-672; author reply 673.

29. Fong AK, Wong SK, Lam CC, Ng EK. Ghrelin level and weight loss after laparoscopic sleeve gastrectomy and gastric mini-bypass for PraderWilli syndrome in Chinese. Obes Surg. 2012;22(11):1742-1745.

30. Crinò A, Schiaffini R, Ciampalini P, et al; Genetic Obesity Study Group of Italian Society of Pediatric endocrinology and diabetology (SIEDP). Hypogonadism and pubertal development in Prader-Willi syndrome. Eur J Pediatr. 2003;162(5):327-333. 
31. Eiholzer U, l'Allemand D, Rousson V, et al. Hypothalamic and gonadal components of hypogonadism in boys with Prader-Labhart-Willi syndrome. J Clin Endocrinol Metab. 2006;91(3):892-898.

32. Pusz ER, Rotenstein D. Treatment of precocious puberty in a female with Prader-Willi syndrome. J Pediatr Endocrinol Metab. 2008;21(5):495-500.

33. Siemensma EP, de Lind van Wijngaarden RF, Otten BJ, de Jong FH, Hokken-Koelega AC. Testicular failure in boys with Prader-Willi syndrome: longitudinal studies of reproductive hormones. J Clin Endocrinol Metab. 2012;97(3):E452-E459.

34. Hirsch HJ, Eldar-Geva T, Benarroch F, Rubinstein O, Gross-Tsur V. Primary testicular dysfunction is a major contributor to abnormal pubertal development in males with Prader-Willi syndrome. $J$ Clin Endocrinol Metab. 2009;94(7):2262-2268.

35. Eldar-Geva T, Hirsch HJ, Rabinowitz R, Benarroch F, Rubinstein O, Gross-Tsur V. Primary ovarian dysfunction contributes to the hypogonadism in women with Prader-Willi Syndrome. Horm Res. 2009;72(3): 153-159.

36. Radicioni AF, Di Giorgio G, Grugni G, et al. Multiple forms of hypogonadism of central, peripheral or combined origin in males with Prader-Willi syndrome. Clin Endocrinol (Oxf). 2012;76(1):72-77.

37. Gross-Tsur V, Hirsch HJ, Benarroch F, Eldar-Geva T. The FSH-inhibin axis in Prader-Willi syndrome: heterogeneity of gonadal dysfunction. Reprod Biol Endocrinol. 2012;10:39.

38. Lee PA, Houk CP. Cryptorchidism. Curr Opin Endocrinol Diabetes Obes. 2013;20(3):210-216.

39. Elena G, Bruna C, Benedetta M, Stefania DC, Giuseppe C. Prader-Willi syndrome: clinical aspects. J Obes. 2012;2012:473941.

40. Pope HG, Kouri EM, Hudson JI. Effects of supraphysiologic doses of testosterone on mood and aggression in normal men: a randomized controlled trial. Arch Gen Psychiatry. 2000;57(2):133-140; discussion $155-156$.

41. Weiss EL, Bowers MB, Mazure CM. Testosterone-patch-induced psychotic mania. Am J Psychiatry. 1999;156(6):969.

42. Cataletto M, Angulo M, Hertz G, Whitman B. Prader-Willi syndrome: A primer for clinicians. Int J Pediatr Endocrinol. 2011;2011(1):12

43. Vogels A, De Hert M, Descheemaeker MJ, et al. Psychotic disorders in Prader-Willi syndrome. Am J Med Genet A. 2004;127A(3):238-243.

44. Eiholzer U, Grieser J, Schlumpf M, l'Allemand D. Clinical effects of treatment for hypogonadism in male adolescents with Prader-LabhartWilli syndrome. Horm Res. 2007;68(4):178-184.

45. Sinnema M, Maaskant MA, van Schrojenstein Lantman-de Valk HM, et al. Physical health problems in adults with Prader-Willi syndrome. Am J Med Genet A. 2011;155A(9):2112-2124.

46. Akefeldt A, Törnhage CJ, Gillberg C. 'A woman with Prader-Willi syndrome gives birth to a healthy baby girl'. Dev Med Child Neurol. 1999;41(11):789-790.

47. Butler JV, Whittington JE, Holland AJ, Boer H, Clarke D, Webb T. Prevalence of, and risk factors for, physical ill-health in people with Prader-Willi syndrome: a population-based study. Dev Med Child Neurol. 2002;44(4):248-255.

48. Butler MG, Haber L, Mernaugh R, Carlson MG, Price R, Feurer ID. Decreased bone mineral density in Prader-Willi syndrome: comparison with obese subjects. Am J Med Genet. 2001;103(3):216-222.

49. Vestergaard P, Kristensen K, Bruun JM, et al. Reduced bone mineral density and increased bone turnover in Prader-Willi syndrome compared with controls matched for sex and body mass index - a cross-sectional study. J Pediatr. 2004;144(5):614-619.

50. Rubin DA, Cano-Sokoloff N, Castner DL, et al. Update on body composition and bone density in children with Prader-Willi syndrome. Horm Res Paediatr. 2013;79(5):271-276.

51. Festen DA, Visser TJ, Otten BJ, Wit JM, Duivenvoorden HJ, Hokken-Koelega AC. Thyroid hormone levels in children with PraderWilli syndrome before and during growth hormone treatment. Clin Endocrinol (Oxf). 2007;67(3):449-456.
52. Vaiani E, Herzovich V, Chaler E, et al. Thyroid axis dysfunction in patients with Prader-Willi syndrome during the first 2 years of life. Clin Endocrinol (Oxf). 2010;73(4):546-550.

53. Tauber M, Diene G, Molinas C, Hébert M. Review of 64 cases of death in children with Prader-Willi syndrome (PWS). Am J Med Genet A. 2008;146(7):881-887.

54. Grugni G, Crinò A, Bosio L, et al; Genetic Obesity Study Group of Italian Society of Pediatric Endocrinology and Diabetology (ISPED). The Italian National Survey for Prader-Willi syndrome: an epidemiologic study. Am J Med Genet A. 2008;146(7):861-872.

55. Nagai T, Obata K, Tonoki H, et al. Cause of sudden, unexpected death of Prader-Willi syndrome patients with or without growth hormone treatment. Am J Med Genet A. 2005;136(1):45-48.

56. de Lind van Wijngaarden RF, Otten BJ, Festen DA, et al. High prevalence of central adrenal insufficiency in patients with Prader-Willi syndrome. J Clin Endocrinol Metab. 2008;93(5):1649-1654.

57. Grugni G, Beccaria L, Corrias A, et al; the Genetic Obesity Study Group of the Italian Society of Pediatric Endocrinology and Diabetology (ISPED). Central adrenal insufficiency in young adults with PraderWilli Syndrome. Clin Endocrinol (Oxf). 2013.

58. Connell NA, Paterson WF, Wallace AM, Donaldson MD. Adrenal function and mortality in children and adolescents with Prader-Willi syndrome attending a single centre from 1991-2009. Clin Endocrinol (Oxf). 2010;73(5):686-688.

59. Farholt S, Sode-Carlsen R, Christiansen JS, Østergaard JR, Høybye C. Normal cortisol response to high-dose synacthen and insulin tolerance test in children and adults with Prader-Willi syndrome. J Clin Endocrinol Metab. 2011;96(1):E173-E180.

60. Butler MG, Meaney FJ. Standards for selected anthropometric measurements in Prader-Willi syndrome. Pediatrics. 1991;88(4):853-860.

61. Cassidy SB, Driscoll DJ. Prader-Willi syndrome. Eur J Hum Genet. 2009;17(1):3-13.

62. Wollmann HA, Schultz U, Grauer ML, Ranke MB. Reference values for height and weight in Prader-Willi syndrome based on 315 patients. Eur J Pediatr. 1998;157(8):634-642.

63. Eiholzer U, Bachmann S, l'Allemand D. Is there growth hormone deficiency in Prader-Willi Syndrome? Six arguments to support the presence of hypothalamic growth hormone deficiency in Prader-Willi syndrome. Horm Res. 2000;53 Suppl 3:44-52.

64. Grugni G, Crinò A, Pagani S, et al; Genetic Obesity Study Group, Italian Society of Pediatric Endocrinology and Diabetology. Growth hormone secretory pattern in non-obese children and adolescents with Prader-Willi syndrome. J Pediatr Endocrinol Metab. 2011;24(7-8): 477-481.

65. Hardin DS. Treatment of short stature and growth hormone deficiency in children with somatotropin (rDNA origin). Biologics. 2008;2(4): 655-661.

66. Lindgren AC, Lindberg A. Growth hormone treatment completely normalizes adult height and improves body composition in PraderWilli syndrome: experience from KIGS (Pfizer International Growth Database). Horm Res. 2008;70(3):182-187.

67. Brambilla P, Bosio L, Manzoni P, Pietrobelli A, Beccaria L, Chiumello G. Peculiar body composition in patients with Prader-Labhart-Willi syndrome. Am J Clin Nutr. 1997;65(5):1369-1374.

68. Carrel AL, Myers SE, Whitman BY, Allen DB. Growth hormone improves body composition, fat utilization, physical strength and agility, and growth in Prader-Willi syndrome: a controlled study. J Pediatr. 1999;134(2):215-221

69. Carrel AL, Myers SE, Whitman BY, Allen DB. Benefits of long-term GH therapy in Prader-Willi syndrome: a 4-year study. J Clin Endocrinol Metab. 2002;87(4):1581-1585.

70. Coupaye M, Lorenzini F, Lloret-Linares C, et al. Growth hormone therapy for children and adolescents with Prader-Willi syndrome is associated with improved body composition and metabolic status in adulthood. J Clin Endocrinol Metab. 2013;98(2):E328-E335. 
71. Siemensma EP, Tummers-de Lind van Wijngaarden RF, Festen DA, et al. Beneficial effects of growth hormone treatment on cognition in children with Prader-Willi syndrome: a randomized controlled trial and longitudinal study. J Clin Endocrinol Metab. 2012;97(7):2307-2314.

72. Reus L, van Vlimmeren LA, Staal JB, Otten BJ, Nijhuis-van der Sanden MW. The effect of growth hormone treatment or physical training on motor performance in Prader-Willi syndrome: a systematic review. Neurosci Biobehav Rev. 2012;36(8):1817-1838.

73. Deal CL, Tony M, Höybye C, Allen DB, Tauber M, Christiansen JS; 2011 Growth Hormone in Prader-Willi Syndrome Clinical Care Guidelines Workshop Participants; EVIDEM Collaboration. Growth hormone research society workshop summary: consensus guidelines for recombinant human growth hormone therapy in Prader-Willi syndrome. $J$ Clin Endocrinol Metab. 2013;98(6):E1072-E1087.

74. Bell J, Parker KL, Swinford RD, Hoffman AR, Maneatis T, Lippe B. Long-term safety of recombinant human growth hormone in children. J Clin Endocrinol Metab. 2010;95(1):167-177.

75. Van Vliet G, Deal CL, Crock PA, Robitaille Y, Oligny LL. Sudden death in growth hormone-treated children with Prader-Willi syndrome. J Pediatr. 2004;144(1):129-131.

76. Eiholzer U. Deaths in children with Prader-Willi syndrome. A contribution to the debate about the safety of growth hormone treatment in children with PWS. Horm Res. 2005;63(1):33-39.

77. Festen DA, de Weerd AW, van den Bossche RA, Joosten K, Hoeve H, Hokken-Koelega AC. Sleep-related breathing disorders in prepubertal children with Prader-Willi syndrome and effects of growth hormone treatment. J Clin Endocrinol Metab. 2006;91(12):4911-4915.

78. Festen DA, de Weerd AW, van den Bossche RA, Joosten K, Hoeve H, Hokken-Koelega AC. Sleep-related breathing disorders in prepubertal children with Prader-Willi syndrome and effects of growth hormone treatment. J Clin Endocrinol Metab. 2006;91(12):4911-4915.

79. Einfeld SL, Kavanagh SJ, Smith A, Evans EJ, Tonge BJ, Taffe J. Mortality in Prader-Willi syndrome. Am J Ment Retard. 2006;111(3):193-198.

80. Stevenson DA, Anaya TM, Clayton-Smith J, et al. Unexpected death and critical illness in Prader-Willi syndrome: report of ten individuals. Am J Med Genet A. 2004;124A(2):158-164.

81. Schrander-Stumpel CT, Curfs LM, Sastrowijoto P, Cassidy SB, Schrander JJ, Fryns JP. Prader-Willi syndrome: causes of death in an international series of 27 cases. Am J Med Genet A. 2004;124A(4): 333-338.

82. O’Donoghue FJ, Camfferman D, Kennedy JD, et al. Sleep-disordered breathing in Prader-Willi syndrome and its association with neurobehavioral abnormalities. J Pediatr. 2005;147(6):823-829.
83. Williams K, Scheimann A, Sutton V, Hayslett E, Glaze DG. Sleepiness and sleep disordered breathing in Prader-Willi syndrome: relationship to genotype, growth hormone therapy, and body composition. J Clin Sleep Med. 2008;4(2):111-118.

84. DeMarcantonio MA, Darrow DH, Gyuricsko E, Derkay CS. Obstructive sleep disorders in Prader-Willi syndrome: The role of surgery and growth hormone. Int J Pediatr Otorhinolaryngol. 2010;74(11):1270-1272.

85. Lindgren AC, Hellström LG, Ritzén EM, Milerad J. Growth hormone treatment increases $\mathrm{CO}(2)$ response, ventilation and central inspiratory drive in children with Prader-Willi syndrome. Eur J Pediatr. 1999; 158(11):936-940

86. Myers SE, Carrel AL, Whitman BY, Allen DB. Sustained benefit after 2 years of growth hormone on body composition, fat utilization, physical strength and agility, and growth in Prader-Willi syndrome. J Pediatr. 2000;137(1):42-49.

87. Haqq AM, Stadler DD, Jackson RH, Rosenfeld RG, Purnell JQ, LaFranchi SH. Effects of growth hormone on pulmonary function, sleep quality, behavior, cognition, growth velocity, body composition, and resting energy expenditure in Prader-Willi syndrome. J Clin Endocrinol Metab. 2003;88(5):2206-2212.

88. Miller J, Silverstein J, Shuster J, Driscoll DJ, Wagner M. Short-term effects of growth hormone on sleep abnormalities in Prader-Willi syndrome. J Clin Endocrinol Metab. 2006;91(2):413-417.

89. Nixon GM, Rodda CP, Davey MJ. Longitudinal association between growth hormone therapy and obstructive sleep apnea in a child with Prader-Willi syndrome. J Clin Endocrinol Metab. 2011;96(1):29-33.

90. de Lind van Wijngaarden RF, Siemensma EP, Festen DA, et al. Efficacy and safety of long-term continuous growth hormone treatment in children with Prader-Willi syndrome. J Clin Endocrinol Metab. 2009;94(11):4205-4215.

91. Katz-Salamon M, Lindgren AC, Cohen G. The effect of growth hormone on sleep-related cardio-respiratory control in Prader-Willi syndrome. Acta Paediatr. 2012;101(6):643-648.

92. Al-Saleh S, Al-Naimi A, Hamilton J, Zweerink A, Iaboni A, Narang I. Longitudinal evaluation of sleep-disordered breathing in children with Prader-Willi Syndrome during 2 years of growth hormone therapy. J Pediatr. 2013;162(2):263-268. e1

93. Whitman BY, Myers SE. Prader-Willi syndrome and growth hormone therapy: take a deep breath and weigh the data. J Pediatr. 2013;162(2): 224-226.
Pediatric Health, Medicine and Therapeutics

\section{Publish your work in this journal}

Pediatric Health, Medicine and Therapeutics is an international, peerreviewed, open access journal publishing original research, reports, editorials, reviews and commentaries. All aspects of health maintenance, preventative measures and disease treatment interventions are addressed within the journal. Practitioners from all disciplines are invited to submit

\section{Dovepress}

their work as well as healthcare researchers and patient support groups. The manuscript management system is completely online and includes a very quick and fair peer-review system. Visit http://www.dovepress.com/ testimonials.php to read real quotes from published authors. 